\title{
Efficient web opening shape and stiffener for large web opening
}

\author{
Xiao Ying $\mathrm{WU}^{1}$, Ling $\mathrm{Xu} \mathrm{LI}^{2}$, Dong Hua $\mathrm{ZHOU}^{3}$ \\ ${ }^{1}$ Faculty of Architectural Engineering, Dianchi College of YunnanUniversity, Kunming, Yunnan650000, China \\ ${ }^{2}$ Faculty of Architectural Engineering, Kunming University of Science andTechnology, Kunming, Yunnan 65000, China
}

\begin{abstract}
: to save material circle and hexagon are often used shapes for web opening in praxis; horizontal plates are often welded on web for stiffening large web opening. These common used shape of opening and stiffening way for large opening are proved as inefficient by finite element analyze. There are new shape of opening and new type of stiffener for large opening, which proved to have the best load bearing behavior respectively. More details will be introduced in following.
\end{abstract}

\section{Introduction}

Bending moment and shearing force in a beam will be carried by different part of the beam. For an I-beam, for example, the web takes mainly the shearing force up, the flanges carry the tensile and compressive force due to the bending moment. The bigger the flanges are, the bigger the web is needed. When more cross sectional area of web is required, the depth of web will be generally increased in stead of raising its width. Because the increasing depth of web makes the distance between flanges greater, as the result the internal level arm and moment bearing capacity become also greater. Now someone would ask whether the web of a beam has always an appropriate dimension in accordance with the flanges. The answer is no. Generally a web is dimensioned with its ratio of depth to width under consideration of buckling aspect. In respect to cross section of flange the web is usually over dimensioned, that is, in some cases the material strength of web can not be fully utilized and thus some material of web can be saved, for instance, with web openings. Which shapes of web openings (circles, rectangles or others) should be used that the beam has a better load carrying capacity? The design of steel beams with large rectangular openings is an important structural and practical problem which is caused by the need to pass service ducts through the structural zone of floor systems. Careful stiffening of these openings in the beam webs can minimize their
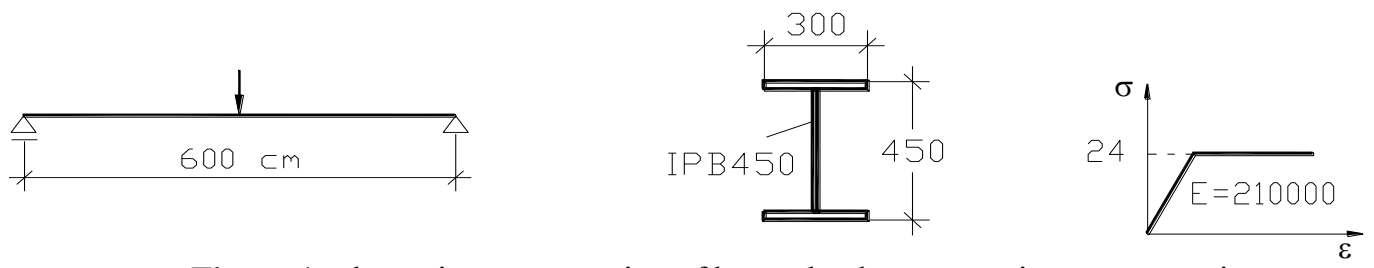

Figure 1 schematic representation of beam, load, cross section, stress-strain curve

From the computed results shown in Figure 2 we can see that beam in case 1 has the greatest load bearing adverse effects on the shear and the bending resistances of steel beams. How to stiffen opening and what kind of stiffener would have the best load bearing behavior? The answer to theses questions all mentioned above is the main content of this paper.

\section{Study of beams with different web opening shapes using nonlinear FEM}

We can be inspired from struts of a trussed framework. Beside struts or post there are only triangular hollow areas. If we choose triangular shape as web opening on an I-beam, what would happen, will this have a better load bearing behavior than those very commonly used, such as circle or hexagon? To answer this question a wide-flange beam IPB450 with following three different web openings is computed with ANSYS program:

1) Triangular openings

2) Circular openings

3) Hexagonal openings

In odder to comparison from each other all openings have the same hollow area, it means, all beams have also the same web area in elevation. In the analyzing the nonlinear material behavior and the geometric symmetry in direction of breadth are taken into account. That is, only one half beam is modeled in direction of width. The beam and its cross section as well as the stress-strain relationship used in analyses are shown in Figure 1.

\footnotetext{
* Corresponding author:758975451@qq.com
} 
lower ultimate failure loads.

Plastic moment of flange is obtained by Eqs. (1):

$M_{p l}=15 \times 2.6 \times 24 \times(45-2.6)=39686.4 \mathrm{kNcm}$

$$
P=\frac{4 \times M_{p l}}{L}=\frac{4 \times 39686.4}{600}=264.6 \mathrm{kN}
$$

(1)

Then the bearing load due to $M_{p l}$ would be

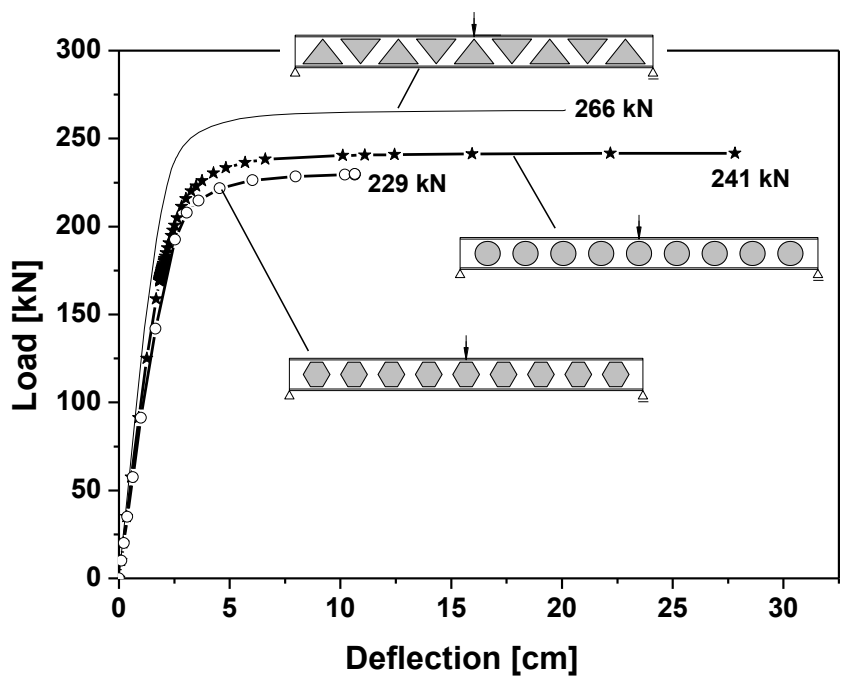

Figure 2 load-deflection curves

The reason for the different responses shown in Figure 2 can be clarified as the following:

1. The approximate resultant of all principle stresses in a web for case 1 as shown in Figure 3 run into a intersection point at flange and no flange is thereby subjected to vertical shearing force, while other two cases show a opposite behavior, that is, there is no intersection point of the approximate resultant of all principle stresses, the part of flange will subjected to local bending.
2. In each web strut of case 1 there is only one single stress state, namely one principle stress state, while in tow other cases there is a combined stress state in each web strut, that are the tensile and compressive principle stresses. As we know, a combined stress with different sign leads to lower stress failure criteria than a single stress state.

3. The principle stresses in web of case 1 are fairly uniformly distributed and this is not so in case 2 and 3 .



Figure 3 principle stress

\section{Study of beams with different stiffeners for large web opening using nonlinear FEM}

How most efficiently stiffening large Opening is another key point of this paper. To make this clear, beams with different stiffener for web opening are investigated and one beam with the same web opening but without any stiffener is also computed for comparison. Four cases being investigated are shown in Figure 4: 
1) Opening with two slanting plates as struts

2) Opening with a semicircle as arc

3) Opening with two horizontal plates

4) Opening without any stiffener
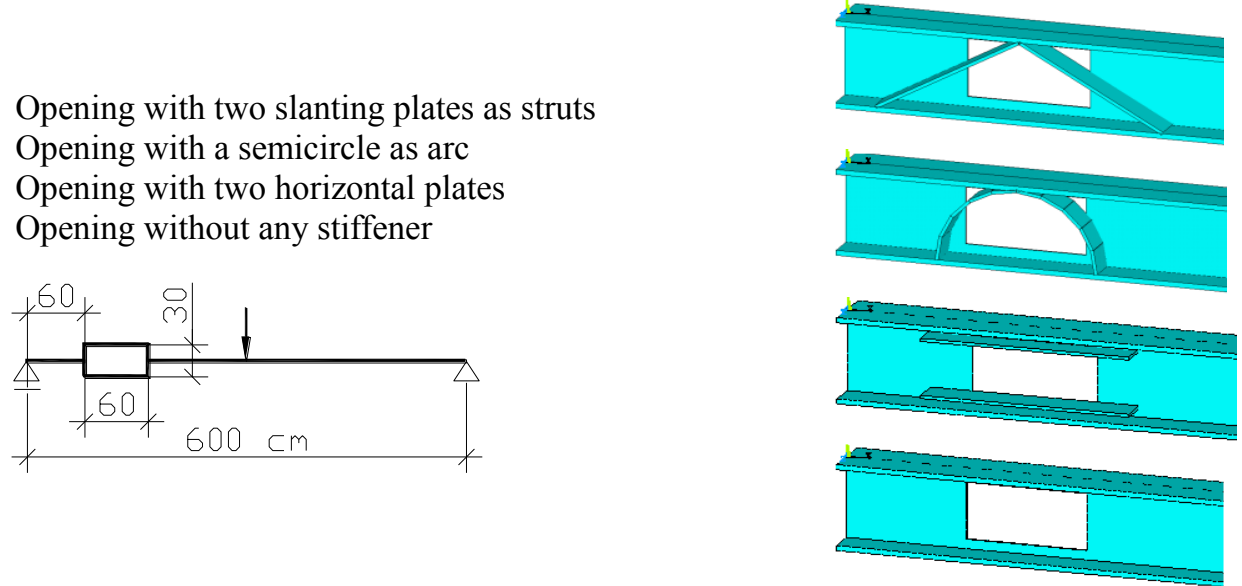

Figure 4 schematic representation of beam (link) and stiffener oblique view (right)

In the analyses the same steel wide-flange shape and the same stress-strain relationship used in preceding point 2 are adopted. The computed load-deflection curves shown in Figure 5 indicate that the stiffener in case 1 and 2 are most efficient, with which beams have the largest failure load and behave ductile. Although the beam with traditional stiffener in case 3 has a considerable higher failure load than beam of case 4 without any stiffening, but lower than beam of case 1 and 2, besides the beam of case 3 behaves very brittle.

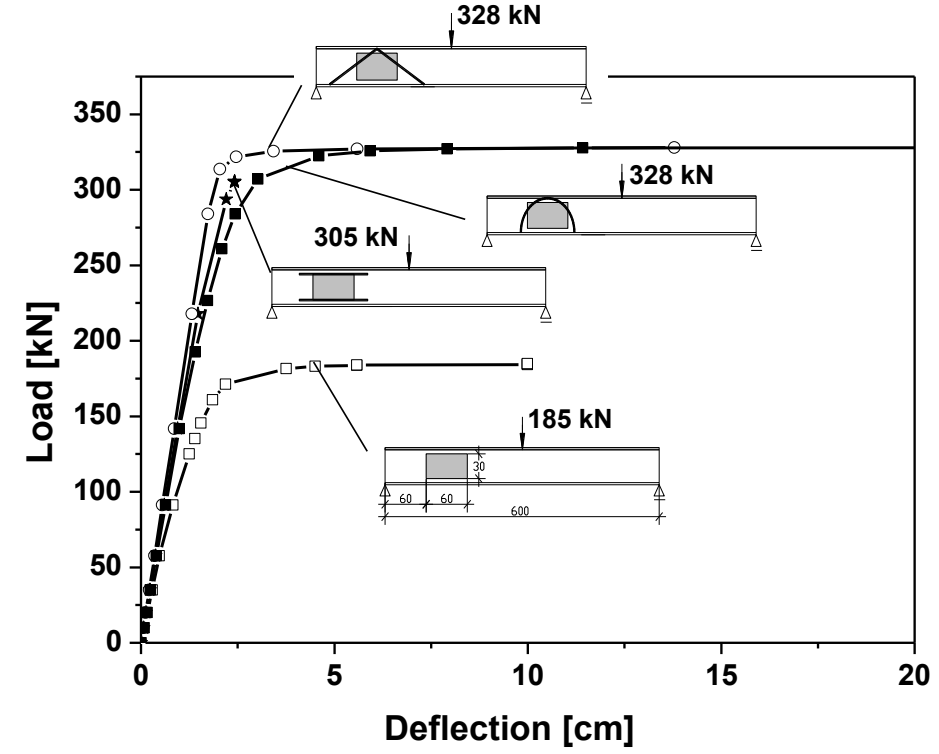

Figure 5 load-deflection curves

From additional results as shown in Figure 6 and 7 we can see more deeply what has happened in the beams. In Figure 6 and 7 the stress ratio and von Mises plastic strain are represented respectively at their own failure load levels. The stress ratio means the ratio of equivalent stress to yield stress. Through these computed results the following special features can be summarized:

1) Beams of case 1 and 2 fail to exploitation of material strength at midpoint of span, while in case 3 and 4 the material fail at opening instead of at center of span.

2) The efficient grade of stiffening of opening is decreased in order of case 1 to case 3 . With this decreased grade the failure places transfer from center of span to the region of opening. 

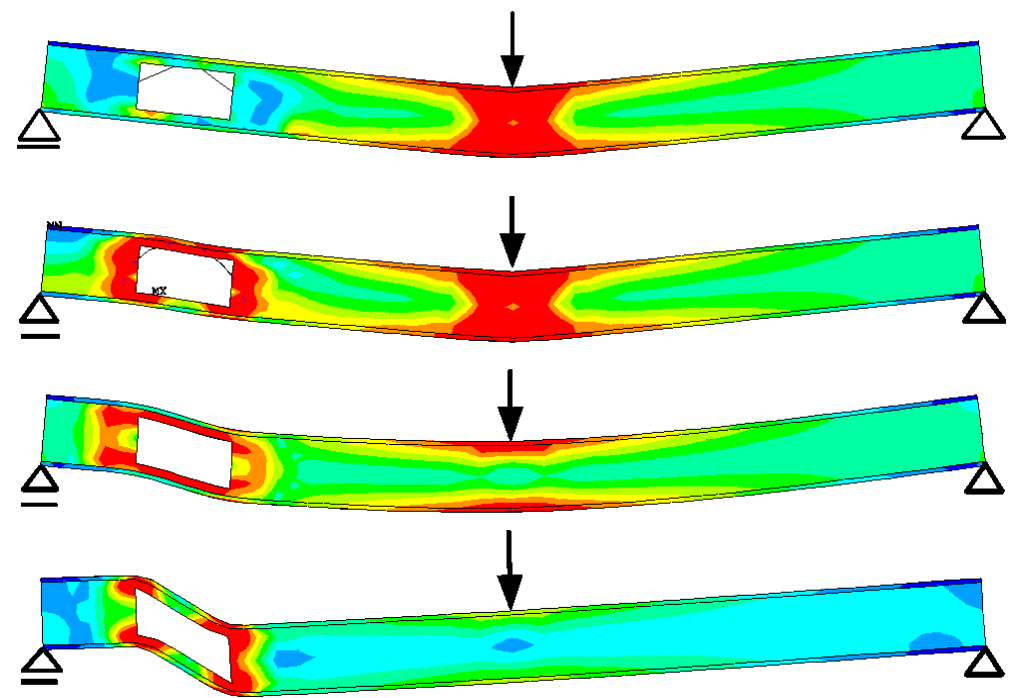

Figure 6 stress ratio (the ratio of equivalent stress to yield stress)

From von Mises plastic strain shown in Figure 7 it exploitation of material in the center of span in case 1 can be confirmed the feature described above, namely and 2 and in the region of opening in case 3 and 4 .

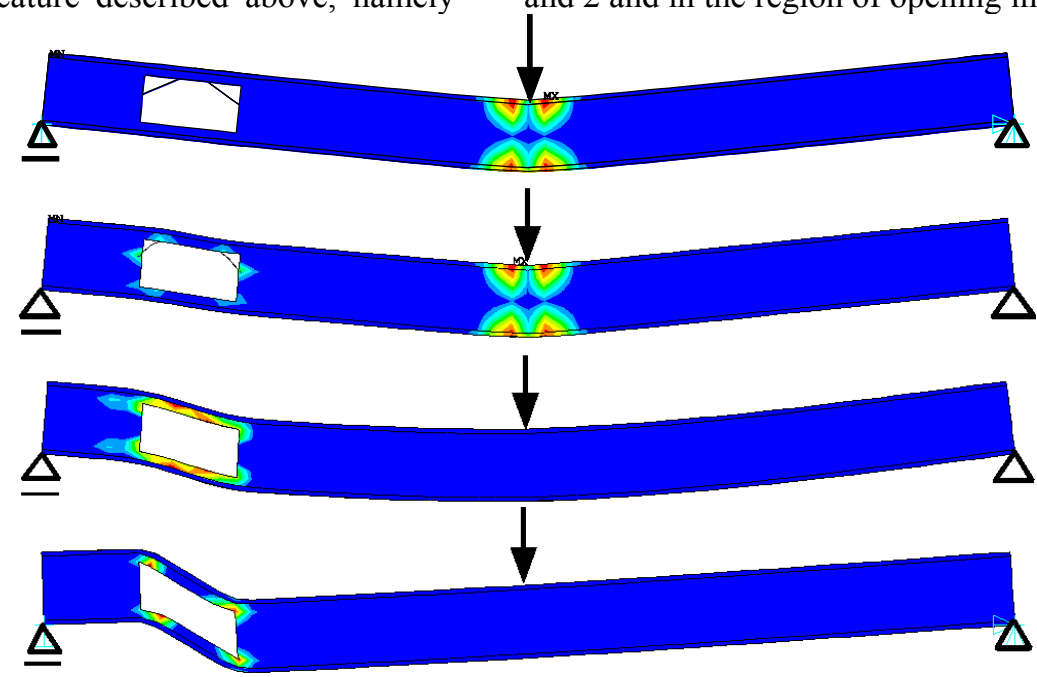

Figure 7 von Mises plastic strain

It is interesting to look at region of opening of case 3 and 4 closely; they both fail at rest web material over and under opening, but the causes led to failure are quite different. The strength of rest webs over and under opening in case 3 is exploited by shear stress, and

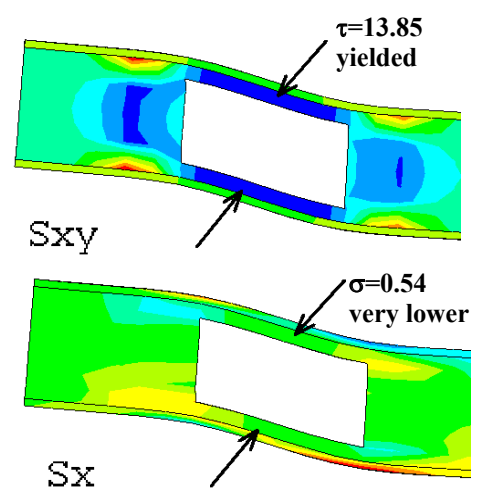

Figure 7 shear stress (Sxy) and normal stress (Sx) in case 3 (link) and 4 (right)

therefore the normal stress due to bending moment is there very small. In case 4 it shows an opposite behavior, the rest webs failed to normal stress due to bending moment instead of shearing force.

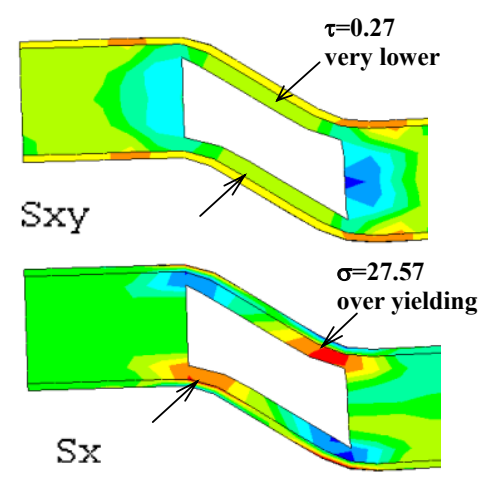

We can very well inspired form load bearing mechanism of the strut of trussed framework by choosing opening shapes or stiffener for large opening. Through the 
analyses carried out in this paper the following important features can be summarized:

1. Opening with triangular shape provides a better bearing behavior than those with traditional opening shapes like circle and hexagon.

2. Triangular stiffener over the opening is the best way to stiffen the large web opening.

3. Beams with the triangular opening shape or beams with triangular stiffeners behave just like slanting struts of trussed framework and present a very good load bearing behavior, high ultimate failure load and ductile deformation.

4. Traditional opening shape like circle and hexagon as well as traditional stiffening way like using horizontal plates has their disadvantage and they should therefore replaced by those mentioned above.

\section{Acknowledgments}

This work was financially supported by the National Natural Science Foundation (51668027 and 51468026).

\section{References}

1. Bode, H., Ramm, W. und Zhou, D.: Physikalisch nichtlineare Berechnungen von Verbundträgern mit Stegöffnungen mit dem Programmpaket ANSYS. Verbundkonstruktionen Neues aus Forschung, Entwicklung und Normung Beiträge zur Fachtagung an der Universität Kaiserslautern (Juli 1997)

2. Bode, H., Stengel, J. und Zhou, D.: Composite Beam Test For A New High-Rise Building, Engineering Foundation Conference, Composite Construction III, Irsee, Germany, June 1996.

3. Donghua Zhou: Tragverhalten von Einfeldverbundträgern mit Stegöffnungen, Stahlbau 3/2004)

4. Donghua Zhou: Besonderheiten von Durchlaufträgern mit Stegöffnungen, Stahlbau 5/2004) 